\title{
Is Evidence of Evidence Evidence? Screening-Off vs. No-Defeaters
}

\author{
William Roche
}

Department of Philosophy, Texas Christian University, Fort Worth, TX, USA, e-mail: w.roche@tcu.edu

ABSTRACT: I argue elsewhere (Roche 2014) that evidence of evidence is evidence under screening-off. Tal and Comesaña (2017) argue that my appeal to screening-off is subject to two objections. They then propose an evidence of evidence thesis involving the notion of a defeater. There is much to learn from their very careful discussion. I argue, though, that their objections fail and that their evidence of evidence thesis is open to counterexample.

KEYWORDS: Comesaña, Evidence of Evidence, No-Defeaters Condition, Screening-Off Condition, Tal, Transitivity in Evidence

\section{Introduction}

I argue elsewhere (Roche 2014) that evidence of evidence is evidence under screening-off. I argue, in fact, for four distinct theses to that effect. The last of them can be put as follows:

EEE $_{S O C}$ If (i) $\quad \operatorname{Pr}\left(H_{1} \mid E\right)>\operatorname{Pr}\left(H_{1}\right)$ where $H_{1}$ is the proposition that $H_{2}$ 's
$\operatorname{probability}$ given $S^{\prime}$ s total evidence is high,
(ii) $\operatorname{Pr}\left(H_{2} \mid H_{1}\right)>\operatorname{Pr}\left(H_{2}\right)$,
and $\begin{aligned} \text { (iii) } \operatorname{Pr}\left(H_{2} \mid H_{1} \& E\right) \geq \operatorname{Pr}\left(H_{2} \mid H_{1}\right) \\ \operatorname{Pr}\left(H_{2} \mid \neg H_{1} \& E\right) \geq \operatorname{Pr}\left(H_{2} \mid \neg H_{1}\right),\end{aligned}$
then (iv) $\operatorname{Pr}\left(H_{2} \mid E\right)>\operatorname{Pr}\left(H_{2}\right)$.

(Here the tacit quantification is over any propositions $E, H_{1}$, and $H_{2}$ and any subject $S$. Similar points are true of TIP $\mathrm{SOC}_{\mathrm{S}}, \mathrm{EEE}_{\mathrm{NDC}}, \mathrm{EEE}^{*}{ }_{\mathrm{NDC}}, \mathrm{TIP}_{\mathrm{NDC}}, \mathrm{EEE}^{* *}{ }_{\mathrm{NDC}}, \mathrm{TIP}_{\mathrm{NDC}}$, and TIP** ${ }_{\text {NDC }}$ below.) Let "evidence-HP" be evidence in the sense of high probability and "evidence-IP" be evidence in the sense of increase in probability. ${ }^{1}$ Then EEE $\mathrm{SOC}_{\text {says }}$ that if (i) $E$ is evidence-IP for $H_{1}$ where $H_{1}$ is the proposition that $S$ 's total evidence is evidence-HP

\footnotetext{
${ }^{1}$ These are but two senses of evidence in the literature. See Douven (2011), Roche (2012b, 2015), and Roche and Shogenji (2014b).
} 
for $H_{2}$, (ii) $H_{1}$ is evidence-IP for $H_{2}$, and (iii) $H_{1}$ screens-off $E$ from $H_{2}$ in that $E$ has no negative impact on $H_{2}$ 's probability given the truth or falsity of $H_{1}$, then (iv) $E$ is evidenceIP for $\mathrm{H}_{2}{ }^{2,3}$

The argument behind $\mathrm{EEE}_{\mathrm{SOC}}$ is straightforward. $\mathrm{EEE}_{\mathrm{SOC}}$ is a special case of the more general thesis that evidence-IP is transitive under screening-off:

$$
\begin{aligned}
& \mathrm{TIP}_{\mathrm{SOC}} \text { If (i) } \operatorname{Pr}\left(H_{1} \mid E\right)>\operatorname{Pr}\left(H_{1}\right) \text {, } \\
& \text { (ii) } \operatorname{Pr}\left(H_{2} \mid H_{1}\right)>\operatorname{Pr}\left(H_{2}\right) \text {, } \\
& \text { and } \\
& \text { (iii) } \operatorname{Pr}\left(H_{2} \mid H_{1} \& E\right) \geq \operatorname{Pr}\left(H_{2} \mid H_{1}\right) \\
& \operatorname{Pr}\left(H_{2} \mid \neg H_{1} \& E\right) \geq \operatorname{Pr}\left(H_{2} \mid \neg H_{1}\right), \\
& \text { then (iv) } \operatorname{Pr}\left(H_{2} \mid E\right)>\operatorname{Pr}\left(H_{2}\right) \text {. }
\end{aligned}
$$

The difference with $\mathrm{TIP}_{\mathrm{SOC}}$, as compared to $\mathrm{EEE}_{\mathrm{SOC}}$, is that the first condition in $\mathrm{TIP}_{\mathrm{SOC}}$ 's antecedent can hold even if $H_{1}$ is not the proposition that $H_{2}$ 's probability given $S$ 's total

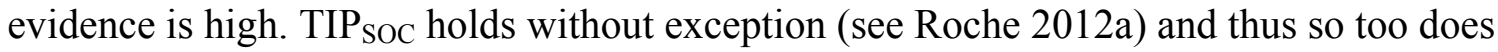
EEE $_{\text {SOC. }}$.

Imagine a case where initially you have a low credence in:

$H_{2} \quad$ The departmental meeting is scheduled for 3:30 today.

You then learn the following about a trusted colleague:

$$
\text { E John has a high credence in } H_{2} \text {. }
$$

Now consider the following:

$H_{1} \quad$ John's total evidence is evidence-HP for $H_{2}$.

You do not know all the details of John's total evidence. But, still, it seems clear that $E$ is evidence-IP for $H_{1}$ and that $H_{1}$, in turn, is evidence-IP for $H_{2}$. It also seems clear that $E$ is

\footnotetext{
${ }^{2}$ Moretti (2016b) argues for a related but distinct EEE thesis involving screening-off.

${ }^{3} \mathrm{EEE}_{\mathrm{SOC}}$ 's screening-off condition is a "negative-impact" screening-off condition. There is also a "no-impact" screening-off condition to the effect that $E$ has no impact on $\mathrm{H}_{2}$ 's probability given the truth or falsity of $H_{1}$, and a "positive-impact" screening-off condition to the effect that $E$ has no positive impact on $H_{2}$ 's probability given the truth or falsity of $H_{1}$. See Roche and Shogenji (2014a) for relevant discussion.
} 
evidence-IP for $\mathrm{H}_{2}$. There are counterexamples, though, to the thesis that evidence-IP is transitive. Is the case at hand a case in point?

If what I argue elsewhere (Roche 2014) is right, then the answer is negative. This is because the case at hand is a case where $H_{1}$ screens-off $E$ from $H_{2}$ (in that $E$ has no negative impact on $H_{2}$ 's probability given the truth or falsity of $H_{1}$ ) and thus the third condition in

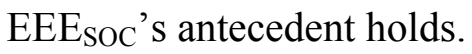

Tal and Comesaña (2017), hereafter "T\&C", argue that my appeal to screening-off is subject to two objections. They write:

First, it is not clear what the evidential relevance of the screening-off conditions is, and so even if they worked flawlessly we would not have a deep understanding of the resulting principle. Second, they do not work flawlessly, for the screening-off conditions are sufficient but not necessary for evidential transitivity. (T\&C 2017, p. 107)

Here by "screening-off conditions" they have in mind, first, the condition that $\operatorname{Pr}\left(H_{2} \mid H_{1} \&\right.$ $E) \geq \operatorname{Pr}\left(H_{2} \mid H_{1}\right)$ and, second, the condition that $\operatorname{Pr}\left(H_{2} \mid \neg H_{1} \& E\right) \geq \operatorname{Pr}\left(H_{2} \mid \neg H_{1}\right)$. They call the former "the positive screening-off condition" and the latter "the negative screening-off condition".

$\mathrm{T} \& \mathrm{C}$ then propose an alternative EEE thesis. They continue the passage above as follows:

In the next section we argue that the right fix for the right version of the EEE principle appeals not to screening-off conditions, but to the notion of a defeater. Defeaters wear their epistemic relevance on their sleeves. Moreover, we will argue that a suitable addition of a no-defeaters condition provides a necessary as well as a sufficient condition for evidence of evidence to be evidence. (T\&C 2017, p. 107)

Their proposed alternative EEE thesis can be put as follows:

EEE $_{\mathrm{NDC}}$ If (i) $\operatorname{Pr}\left(H_{1} \mid E\right)>\operatorname{Pr}\left(H_{1}\right)$ to degree $\alpha$ where $H_{1}$ is the proposition that there is a proposition $E^{*}$ such that $E^{*}$ is true and is evidence-IP for $\mathrm{H}_{2}$ to degree $\beta$,

(ii) $\operatorname{Pr}\left(H_{2} \mid H_{1}\right)>\operatorname{Pr}\left(H_{2}\right)$ to degree $\gamma$,

and

(iii) $\operatorname{Pr}\left(H_{2} \mid H_{1} \& E\right)>\operatorname{Pr}\left(H_{2}\right)$ to degree $\delta$, then (iv) there is a degree $\varepsilon$ such that $\operatorname{Pr}\left(H_{2} \mid E\right)>\operatorname{Pr}\left(H_{2}\right)$ to degree $\varepsilon$. 
This thesis differs from $\mathrm{EEE}_{\mathrm{SOC}}$ in at least four key respects. ${ }^{4}$ First, there is no mention in EEE $_{\mathrm{NDC}}$ of a subject. Second, the evidence at issue in $H_{1}$ is evidence-IP. Third, there is reference in $\mathrm{EEE}_{\mathrm{NDC}}$ to degrees of evidence-IP. ${ }^{5}$ Fourth, the third condition in $\mathrm{EEE}_{\mathrm{NDC}}$ 's antecedent is a "no-defeaters" condition.

There is much to learn from T\&C's very careful discussion. I aim to show, though, that their objections to my appeal to screening-off fail and that $\mathrm{EEE}_{\mathrm{NDC}}$ is open to counterexample. ${ }^{6}$

${ }^{4}$ The second condition in EEE ${ }_{\mathrm{NDC}}$ 's antecedent is suppressed in T\&C's formulation of their EEE thesis (which they call "Existential EEE1 de dicto no defeat"). See T\&C (2017, p. 110, en. 7).

${ }^{5}$ See Moretti (2016a) for discussion of a thesis like $\mathrm{EEE}_{\mathrm{NDC}}$ but with no reference to degrees of evidence-IP.

${ }^{6}$ I take issue with certain other parts of T\&C's discussion. First, consider:

What is this case [i.e., Fitelson's case] a counterexample to? It is uncontroversially a counterexample to a de re reading of EEE1 .... But Roche suggests that the case is not a counterexample to EEE1 de dicto .... According to Roche, Fitelson's case is not a counterexample to EEE1 de dicto because we already know the following existential proposition: there is some proposition that John has which is evidence for H'. (T\&C 2017, p. 100, emphasis original)

$\mathrm{T} \& \mathrm{C}$ then argue that my argument fails. It is not the case, though, that I argue that Fitelson's case is not a counterexample to EEE1 de dicto. I have in mind a thesis in which there is no reference to degrees of evidence-IP. I call the thesis in question "EEE ${ }_{U}$ " (see Roche 2014, p. 120). Given this, and given that there is reference in EEE1 de dicto to degrees of evidenceIP, it follows that I have in mind a thesis distinct from EEE1 de dicto. Second, consider:

Roche seems to think that the point holds only under a Williamsonian conception of evidence possession, and thus hedges by saying that Fitelson's case only may be a counterexample to (in effect) EEE1 de dicto. But Roche's point holds (if at all) on any sane conception of evidence-possession, not only a Williamsonian one. (T\&C 2017, p. 110 , en. 8 , emphasis original).

What I say (in effect) is that the point in question holds if a Williamsonian conception is assumed. This, of course, does not mean that the point holds only if a Williamsonian conception is assumed. See Roche (2014, p. 121, fn. 6). The reason why I hedge and use the expression "might" was because of a worry to the effect that if $S$ believes $E^{*}$ as a result of an 


\section{Transitivity in evidence-IP: SOC versus NDC}

There are counterexamples to the thesis that evidence-IP is transitive. It will help in terms of understanding the rationale behind my appeal to screening-off to understand why there are counterexamples to the thesis that evidence-IP is transitive.

Consider the following theorem of the probability calculus:

$$
\begin{aligned}
\operatorname{Pr}\left(H_{2} \mid E\right)-\operatorname{Pr}\left(H_{2}\right)= & {\left[\operatorname{Pr}\left(H_{1} \mid E\right)-\operatorname{Pr}\left(H_{1}\right)\right]\left[\operatorname{Pr}\left(H_{2} \mid H_{1}\right)-\operatorname{Pr}\left(H_{2}\right)\right] } \\
& {\left[\operatorname{Pr}\left(\neg H_{1} \mid E\right)-\operatorname{Pr}\left(\neg H_{1}\right)\right]\left[\operatorname{Pr}\left(H_{2} \mid \neg H_{1}\right)-\operatorname{Pr}\left(H_{2}\right)\right]+} \\
& \operatorname{Pr}\left(H_{1} \mid E\right)\left[\operatorname{Pr}\left(H_{2} \mid H_{1} \& E\right)-\operatorname{Pr}\left(H_{2} \mid H_{1}\right)\right] \\
& \operatorname{Pr}\left(\neg H_{1} \mid E\right)\left[\operatorname{Pr}\left(H_{2} \mid \neg H_{1} \& E\right)-\operatorname{Pr}\left(H_{2} \mid \neg H_{1}\right)\right]+
\end{aligned}
$$

This theorem is due to Shogenji (forthcoming) and thus shall hereafter be referred to as "Shogenji's theorem". Let the first addend on the right be "A1", the second addend on the right be "A2", the third addend on the right be "A3", and the fourth addend on the right be "A4". Suppose that $E$ is evidence-IP for $H_{1}$ and that $H_{1}$ is evidence-IP for $H_{2}$. Then each of $\mathrm{A} 1$ and $\mathrm{A} 2$ is positive and thus $\mathrm{A} 1+\mathrm{A} 2$ is positive. It does not follow, though, that $\mathrm{A} 1+\mathrm{A} 2+\mathrm{A} 3+\mathrm{A} 4$ is positive, because it could be that $\mathrm{A} 3+\mathrm{A} 4$ is negative and greater than or equal to in absolute value $\mathrm{A} 1+\mathrm{A} 2$. All counterexamples to the thesis that evidence-IP is transitive are cases where $\mathrm{A} 1+\mathrm{A} 2$ is positive but $\mathrm{A} 3+\mathrm{A} 4$ is negative and greater than or equal to in absolute value $\mathrm{A} 1+\mathrm{A} 2$.

Suppose, to illustrate, that a card is randomly drawn from a standard and well-shuffled deck of cards. Let $E$ be the proposition that the card drawn is not a Heart, $H_{1}$ be the proposition that the card drawn is a Diamond, and $H_{2}$ be the proposition that the card drawn is a Red. Then, since $E$ is evidence-IP for $H_{1}$ and $H_{1}$ is evidence-IP for $H_{2}, \mathrm{~A} 1+\mathrm{A} 2$ is positive:

$$
\left[\frac{1}{3}-\frac{1}{4}\right]\left[1-\frac{1}{2}\right]+\left[\frac{2}{3}-\frac{3}{4}\right]\left[\frac{1}{3}-\frac{1}{2}\right]=\frac{1}{18}
$$

$\mathrm{A} 3+\mathrm{A} 4$, however, is negative and greater than or equal to in absolute value $\mathrm{A} 1+\mathrm{A} 2$ :

$$
\left[\frac{1}{3}\right][1-1]+\left[\frac{2}{3}\right]\left[0-\frac{1}{3}\right]=-\frac{2}{9}
$$

inference, then $E^{*}$ is not included in $S^{\prime}$ s total evidence even if there is a proposition $E$ such that $E$ is included in $S^{\prime}$ s total evidence and $E^{*}$ is entailed by $E$. 
It follows that $\mathrm{A} 1+\mathrm{A} 2+\mathrm{A} 3+\mathrm{A} 4$ is negative and that so too is $\operatorname{Pr}\left(H_{2} \mid E\right)-\operatorname{Pr}\left(H_{2}\right)$. This case is thus a counterexample to the thesis that evidence-IP is transitive. ${ }^{7}$

It is clear from Shogenji's theorem than any condition that is sufficient for transitivity in evidence-IP is a condition that guarantees that, when $E$ is evidence-IP for $H_{1}$ and $H_{1}$ is evidence-IP for $\mathrm{H}_{2}$, it is not the case that A3+A4 is negative and greater than or equal to in absolute value $\mathrm{A} 1+\mathrm{A} 2$. There is simply no way around it.

Now consider the condition:

$$
\text { SOC } \quad \operatorname{Pr}\left(H_{2} \mid H_{1} \& E\right) \geq \operatorname{Pr}\left(H_{2} \mid H_{1}\right) \text { and } \operatorname{Pr}\left(H_{2} \mid \neg H_{1} \& E\right) \geq \operatorname{Pr}\left(H_{2} \mid \neg H_{1}\right)
$$

This is the screening-off condition in $\mathrm{EEE}_{\mathrm{SOC}}$ and TIP $\mathrm{POC}_{\text {SOC }}$ SOC guarantees that each of A3 and A4 is non-negative and thus guarantees that, when $E$ is evidence-IP for $H_{1}$ and $H_{1}$ is evidence-IP for $\mathrm{H}_{2}$, it is not the case that A3+A4 is negative and greater than or equal to in absolute value $\mathrm{A} 1+\mathrm{A} 2$. It follows that $\mathrm{TIP}_{\mathrm{SOC}}$ holds without exception and that so too does EEE $_{\text {SOC. }}$

It is important to note that neither conjunct of SOC is sufficient for transitivity in evidence-IP. Return to the card case above. $E$ is evidence-IP for $H_{1}, H_{1}$ is evidence-IP for $\mathrm{H}_{2}$, and the first conjunct of SOC holds (because each probability equals 1 ). But it is not the case that $E$ is evidence-IP for $\mathrm{H}_{2}$. Hence the first conjunct of SOC is not sufficient for transitivity in evidence-IP. Now let $E$ be the proposition that the card drawn is a Club, the Ace of Spades, or the Ace of Hearts, $H_{1}$ be the proposition that the card drawn is not a Spade, and $H_{2}$ be the proposition that the card drawn is a Red. Then $E$ is evidence-IP for $H_{1}$, $H_{1}$ is evidence-IP for $H_{2}$, and the second conjunct of SOC holds (because each probability equals 0). But, as $\operatorname{Pr}\left(H_{2} \mid E\right)=1 / 15<1 / 2=\operatorname{Pr}\left(H_{2}\right)$, it is not the case that $E$ is evidence-IP for $H_{2}$. Hence the second conjunct of SOC is not sufficient for transitivity in evidence-IP.

T\&C suggest that the second conjunct of SOC be dropped and that the first conjunct be replaced by a no-defeaters condition:

NDC $\quad \operatorname{Pr}\left(H_{2} \mid H_{1} \& E\right)>\operatorname{Pr}\left(H_{2}\right)$

This is the no-defeaters condition in $\mathrm{EEE}_{\mathrm{NDC}}$. NDC is weaker than the first conjunct of SOC on the assumption that $H_{1}$ is evidence-IP for $H_{2}$. Any case where $H_{1}$ is evidence-IP for $H_{2}$ and the first conjunct of SOC holds is a case where $\operatorname{Pr}\left(H_{2} \mid H_{1} \& E\right) \geq \operatorname{Pr}\left(H_{2} \mid H_{1}\right)>\operatorname{Pr}\left(H_{2}\right)$ and thus is a case where NDC holds. But some cases where $H_{1}$ is evidence-IP for $H_{2}$ and

\footnotetext{
${ }^{7}$ It is also a counterexample to Hempel's "Special Consequence Condition" (Hempel 1965) understood in terms of evidence-IP: If (i) $E$ is evidence-IP for $H_{1}$ and (ii) $H_{1}$ entails $H_{2}$, then $E$ is evidence-IP for $H_{2}$.
} 
NDC holds are cases where $\operatorname{Pr}\left(H_{2} \mid H_{1}\right)>\operatorname{Pr}\left(H_{2} \mid H_{1} \& E\right)>\operatorname{Pr}\left(H_{2}\right)$ and thus are cases where the first conjunct of SOC does not hold. Is NDC sufficient for transitivity in evidence-IP?

The answer, clearly, is no. NDC is weaker than the first conjunct of SOC on the assumption that $H_{1}$ is evidence-IP for $H_{2}$ and so holds in all cases where the first conjunct of SOC holds and $H_{1}$ is evidence-IP for $H_{2}$. But, as noted above, there are cases where $E$ is evidence-IP for $H_{1}, H_{1}$ is evidence-IP for $H_{2}$, the first conjunct of SOC holds, and yet it is not the case that $E$ is evidence-IP for $H_{2}$. All such cases are counterexamples to the thesis that NDC is sufficient for transitivity in evidence-IP.

$\mathrm{T} \& \mathrm{C}$ acknowledge that my appeal to SOC works. They claim, though, that it works by "brute force". They want to know why it works. This in effect is their first objection to my appeal to SOC. It should be clear, at this point, why my appeal to SOC works:

SOC guarantees that, when $E$ is evidence-IP for $H_{1}$ and $H_{1}$ is evidence-IP for $H_{2}$, it is not the case that $\mathrm{A} 3+\mathrm{A} 4$ is negative and greater than or equal to in absolute value $\mathrm{A} 1+\mathrm{A} 2$.

It should also be clear why an appeal to NDC would not work:

NDC fails to guarantee that, when $E$ is evidence-IP for $H_{1}$ and $H_{1}$ is evidence-IP for $H_{2}$, it is not the case that $\mathrm{A} 3+\mathrm{A} 4$ is negative and greater than or equal to in absolute value $\mathrm{A} 1+\mathrm{A} 2$.

There is simply no getting around the point that any condition that is sufficient for transitivity in evidence-IP is a condition that guarantees that, when $E$ is evidence-IP for $H_{1}$ and $H_{1}$ is evidence-IP for $H_{2}$, it is not the case that A3+A4 is negative and greater than or equal to in absolute value $\mathrm{A} 1+\mathrm{A} 2$.

There is more. Consider what can be called the "Trivial Condition":

TC $\quad \operatorname{Pr}\left(H_{2} \mid E\right)>\operatorname{Pr}\left(H_{2}\right)$

This condition, as with SOC, is sufficient for transitivity in evidence-IP. But TC is not at all interesting. TC is impotent to help explain in a given case why $E$ confirms $H_{2}$ and it is impotent to help in verifying in a given case that $E$ confirms $H_{2}$. SOC is different. It can help explain in a given case why $E$ confirms $H_{2}$ and it can help in verifying in a given case, for example, the case of John and the departmental meeting, that $E$ confirms $\mathrm{H}_{2}{ }^{8,9}$

\footnotetext{
${ }^{8}$ See Roche and Shogenji (2014b) for an argument to the effect that SOC holds in the context of Moore's "proof" of the existence of a material world.

${ }^{9}$ Consider the following conditions (the first of which is the so-called "Dragging Condition" from Kotzen 2012):
} 
What about T\&C's charge that SOC is not necessary for transitivity in evidence-IP? How exactly do T\&C mean for this charge to be understood?

One answer is that they mean for it to be understood as the charge that SOC is not necessary for the relation of "being evidence-IP for" to be transitive, that is, for it to be such that any case where $E$ is evidence-IP for $H_{1}$ and $H_{1}$ is evidence-IP for $H_{2}$ is a case where $E$ is evidence-IP for $\mathrm{H}_{2}$. If this answer is right, then T\&C's charge is clearly correct. This can be seen by considering what can be called the "Weaker Condition":

WC It is not the case that $\mathrm{A} 3+\mathrm{A} 4$ is negative and greater than or equal to in absolute value $\mathrm{A} 1+\mathrm{A} 2$.

This condition is weaker than SOC. Yet it is sufficient for transitivity in evidence-IP.

It turns out, though, that $\mathrm{T} \& \mathrm{C}$ mean for their charge to be understood differently. Their worry is that there are cases where $E$ is evidence-IP for $H_{1}, H_{1}$ is evidence-IP for $H_{2}$, SOC does not hold, and yet $E$ is evidence-IP for $H_{2} \cdot{ }^{10}$ They want a condition $\mathrm{C}$ such that (i) $\mathrm{C}$ is sufficient for transitivity in evidence-IP and (ii) if $E$ is evidence-IP for $H_{1}, H_{1}$ is evidence-IP for $\mathrm{H}_{2}$, and $\mathrm{C}$ does not hold, then $\mathrm{E}$ is not evidence-IP for $\mathrm{H}_{2}$.

It is true that SOC is not a condition of that sort. But note that the same is true of NDC. This can be seen by appeal to a variant of the card cases above. Let $E$ be the proposition that the card drawn is a Two or a Three, $H_{1}$ be the proposition that the card drawn is a Three or a Four, and $H_{2}$ be the proposition that the card drawn is a Two or a Four. $\operatorname{Pr}\left(H_{1} \mid E\right)=1 / 2>$ $2 / 13=\operatorname{Pr}\left(H_{1}\right)$, so $E$ is evidence-IP for $H_{1}$. $\operatorname{Pr}\left(H_{2} \mid H_{1}\right)=1 / 2>2 / 13=\operatorname{Pr}\left(H_{2}\right)$, so $H_{1}$ is

$$
\begin{aligned}
& \operatorname{Pr}\left(H_{2}\right)<\operatorname{Pr}\left(H_{1} \mid E\right) \\
& \operatorname{Pr}\left(H_{2} \& \neg H_{1} \mid E\right) \geq \operatorname{Pr}\left(H_{2} \& \neg H_{1}\right)
\end{aligned}
$$

Each of these conditions is sufficient for transitivity in evidence-IP in the special case where $H_{1}$ entails $H_{2}$. But, unlike SOC, neither of them is sufficient for transitivity in evidence-IP in the general case where it is not required that $H_{1}$ entails $H_{2}$. They thus have no application in cases like the case of John and the departmental meeting. See Roche and Shogenji (2014b) for discussion.

${ }^{10}$ T\&C (2017, p. 111, en. 19) claim in effect that Roche and Shogeniji (2014b) note that the second conjunct of SOC (what T\&C call "the negative screening-off condition") is sufficient but not necessary for transitivity in evidence-IP. This is misleading. Roche and Shogenji (2014b, pp. 807-808) have in mind the special case where $H_{1}$ entails $H_{2}$. It is not the case, and Roche and Shogenji (2014b) do not suggest otherwise, that the second conjunct of SOC is sufficient for transitivity in evidence-IP. 
evidence-IP for $H_{2}$. $\operatorname{Pr}\left(H_{2} \mid H_{1} \& E\right)=0<2 / 13=\operatorname{Pr}\left(H_{2}\right)$, so NDC does not hold. $\operatorname{But} \operatorname{Pr}\left(H_{2} \mid\right.$ $E)=1 / 2>2 / 13=\operatorname{Pr}\left(H_{2}\right)$, so $E$ is evidence-IP for $H_{2}$.

There are conditions of the sort that T\&C want. One is TC. But this condition, as noted above, is not at all interesting. A better condition is WC. This condition, unlike TC, is distinct from the condition that $E$ is evidence-IP for $H_{2}$. There are cases where WC holds but, since in part $E$ is not evidence-IP for $H_{1}$ or $H_{1}$ is not evidence-IP for $H_{2}$, it is not the case that $E$ is evidence-IP for $\mathrm{H}_{2}$.

I see no need to choose between SOC and WC or between theses involving SOC such as $\mathrm{TIP}_{\mathrm{SOC}}$ and $\mathrm{EEE}_{\mathrm{SOC}}$ and similar theses involving WC. They all have their place.

I turn now to $\mathrm{EEE}_{\mathrm{NDC}}$ and some variants of it.

\section{A counterexample to $T \& C$ 's EEE thesis}

Consider the following variant of $\mathrm{EEE}_{\mathrm{NDC}}$ :

$$
\begin{aligned}
& \text { EEE* NDC If (i) } \operatorname{Pr}\left(H_{1} \mid E\right)>\operatorname{Pr}\left(H_{1}\right) \text { where } H_{1} \text { is the proposition that } H_{2} \text { 's } \\
& \text { probability given } S \text { 's total evidence is high, } \\
& \text { (ii) } \operatorname{Pr}\left(H_{2} \mid H_{1}\right)>\operatorname{Pr}\left(H_{2}\right),
\end{aligned}
$$

and

(iii) $\operatorname{Pr}\left(H_{2} \mid H_{1} \& E\right)>\operatorname{Pr}\left(H_{2}\right)$,

then (iv) $\operatorname{Pr}\left(H_{2} \mid E\right)>\operatorname{Pr}\left(H_{2}\right)$.

$\mathrm{EEE}^{*}{ }_{\mathrm{NDC}}$ is a special case of:

$$
\begin{array}{lll}
\mathrm{TIP}_{\mathrm{NDC}} \quad \text { If } & \text { (i) } \operatorname{Pr}\left(H_{1} \mid E\right)>\operatorname{Pr}\left(H_{1}\right), \\
& \text { (ii) } \operatorname{Pr}\left(H_{2} \mid H_{1}\right)>\operatorname{Pr}\left(H_{2}\right),
\end{array}
$$

and

(iii) $\operatorname{Pr}\left(H_{2} \mid H_{1} \& E\right)>\operatorname{Pr}\left(H_{2}\right)$,

then (iv) $\operatorname{Pr}\left(H_{2} \mid E\right)>\operatorname{Pr}\left(H_{2}\right)$.

$\mathrm{TIP}_{\mathrm{NDC}}$, though, is false, for it is not the case that NDC is sufficient for transitivity in evidence-IP. Does it follow that EEE* ${ }_{\mathrm{NDC}}$ too is false?

The answer, it turns out, is negative. It could be that TIP $_{\mathrm{NDC}}$ is false but nonetheless holds without exception in special cases where $H_{1}$ is a proposition about evidence. Consider, for example, the thesis:

EEE** ${ }_{\text {NDC }}$ If (i) $\operatorname{Pr}\left(H_{1} \mid E\right)>\operatorname{Pr}\left(H_{1}\right)$ where $H_{1}$ is the proposition that $S$ has some evidence-IP for $\mathrm{H}_{2}$, 


\section{(ii) $\operatorname{Pr}\left(H_{2} \mid H_{1}\right)>\operatorname{Pr}\left(H_{2}\right)$, \\ and \\ (iii) $\operatorname{Pr}\left(H_{2} \mid H_{1} \& E\right)>\operatorname{Pr}\left(H_{2}\right)$, \\ then (iv) $\operatorname{Pr}\left(H_{2} \mid E\right)>\operatorname{Pr}\left(H_{2}\right)$.}

EEE** ${ }_{\text {NDC }}$ holds without exception if it is assumed both that all subjects have some propositions (with non-extreme unconditional probabilities) as evidence and that if a subject has a proposition as evidence, then she also has any implication (with a non-extreme unconditional probability) of that proposition as evidence. For, if those things are assumed, then there are no cases where the first condition in EEE ${ }^{* *}{ }_{\mathrm{NDC}}$ 's antecedent holds. This is easy to see. Suppose that $S$ has $E^{*}$ as evidence. Then, since $E^{*}$ entails $E^{*} \vee H_{2}$, it follows that $S$ has that disjunction as evidence. Given this, and given that $E^{*} \vee H_{2}$ is entailed by $\mathrm{H}_{2}$, it follows that $E^{*} \vee H_{2}$ is evidence-IP for $H_{2}$ (assuming that $H_{2}$ has a non-extreme unconditional probability). Hence $S$ has some evidence-IP for $H_{2}$. So, though EEE** ${ }_{\text {NDC }}$ is a

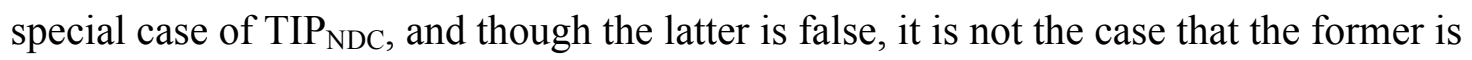
false. ${ }^{11,12}$ Hence the mere fact that $\mathrm{TIP}_{\mathrm{NDC}}$ is false leaves it open that it is not the case that $\mathrm{EEE}^{*}{ }_{\mathrm{NDC}}$, which is a special case of $\mathrm{TIP}_{\mathrm{NDC}}$, is false.

Consider now a different version of the case of John and the departmental meeting. Each of John's credences is either high or not high, either in a proposition for which his total evidence is evidence-HP or not in a proposition for which his total evidence is evidence-HP, and either in a true proposition or not in a true proposition. Suppose that you know that:

(a) $\quad 3 / 5$ of John's credences are high \& in a proposition for which his total evidence is evidence-HP \& in a true proposition

(b) $\quad 1 / 15$ of John's credences are high \& in a proposition for which his total evidence is evidence-HP \& not in a true proposition

(c) 0 of John's credences are high \& not in a proposition for which his total evidence is evidence-HP \& in a true proposition $2 / 27$ of John's credences are high \& not in a proposition for which his total evidence is evidence-HP \& not in a true proposition

\footnotetext{
${ }^{11}$ These points about EEE** ${ }_{\text {NDC }}$ carry over to an EEE thesis put forward in Roche (2014). The thesis in question is called "(EEE'U)" and is like EEE** ${ }_{\mathrm{NDC}}$ except that it has SOC where $\mathrm{EEE}^{* *}{ }_{\mathrm{NDC}}$ has NDC.

${ }^{12}$ See Comesaña and Tal (2015) for a similar point about an EEE thesis discussed in Fitelson (2012).
} 
(e) 0 of John's credences are not high \& in a proposition for which his total evidence is evidence-HP \& in a true proposition

(f) $\quad 0$ of John's credences are not high \& in a proposition for which his total evidence is evidence-HP \& not in a true proposition

(g) $\quad 1 / 4$ of John's credences are not high \& not in a proposition for which his total evidence is evidence-HP \& in a true proposition

(h) $\quad 1 / 108$ of John's credences are not high \& not in a proposition for which his total evidence is evidence-HP \& not in a true proposition

(Note that $3 / 5+1 / 15+0+2 / 27+0+0+1 / 4+1 / 108=1$.) Let $E$ be the proposition that John has a high credence in $H_{2}, H_{1}$ be the proposition that John's total evidence is evidenceHP for $\mathrm{H}_{2}$, and $\mathrm{H}_{2}$ be the proposition that the departmental meeting is scheduled for 3:30 today. Suppose that $\mathrm{H}_{2}$ is one of the propositions in which John has a credence, and that, from your perspective, John's credence in $H_{2}$ is a random member of the set of propositions in which he has a credence. Suppose, further, and consistent with all this, that your probability for $H_{2}$ is 0.85 . Then you should have the following probability distribution:

\begin{tabular}{ccc|c}
$E$ & $H_{1}$ & $H_{2}$ & $\operatorname{Pr}$ \\
\hline $\mathrm{T}$ & $\mathrm{T}$ & $\mathrm{T}$ & $\frac{3}{5}$ \\
\hline $\mathrm{T}$ & $\mathrm{T}$ & $\mathrm{F}$ & $\frac{1}{15}$ \\
\hline $\mathrm{T}$ & $\mathrm{F}$ & $\mathrm{T}$ & 0 \\
\hline $\mathrm{T}$ & $\mathrm{F}$ & $\mathrm{F}$ & $\frac{2}{27}$ \\
\hline $\mathrm{F}$ & $\mathrm{T}$ & $\mathrm{T}$ & 0 \\
\hline $\mathrm{F}$ & $\mathrm{T}$ & $\mathrm{F}$ & 0 \\
\hline $\mathrm{F}$ & $\mathrm{F}$ & $\mathrm{T}$ & $\frac{1}{4}$ \\
\hline $\mathrm{F}$ & $\mathrm{F}$ & $\mathrm{F}$ & $\frac{1}{108}$
\end{tabular}

It follows that:

$$
\operatorname{Pr}\left(H_{1} \mid E\right)=9 / 10>2 / 3=\operatorname{Pr}\left(H_{1}\right)
$$$$
\operatorname{Pr}\left(H_{2} \mid H_{1}\right)=9 / 10>85 / 100=\operatorname{Pr}\left(H_{2}\right)
$$

$$
\operatorname{Pr}\left(H_{2} \mid H_{1} \& E\right)=9 / 10>85 / 100=\operatorname{Pr}\left(H_{2}\right)
$$


(1)

$$
\operatorname{Pr}\left(H_{2} \mid E\right)=81 / 100<85 / 100=\operatorname{Pr}\left(H_{2}\right)
$$

So, $E$ is evidence-IP for $H_{1}$ where $H_{1}$ is the proposition that John's total evidence is evidence-HP for $H_{2}, H_{1}$ is evidence-IP for $H_{2}$, and NDC holds, and yet it is not the case that $E$ is evidence-IP for $\mathrm{H}_{2}$. Hence $\mathrm{EEE}^{*}{ }_{\mathrm{NDC}}$, as with $\mathrm{TIP}_{\mathrm{NDC}}$, is false.

It is unclear at this point whether the same is true of $\mathrm{EEE}_{\mathrm{NDC}}$. This is because it is unclear at this point how exactly $\mathrm{EEE}_{\mathrm{NDC}}$ is to be understood. T\&C never specify how degree of evidence-IP is to be measured. They use expressions like "entailing evidence" and "evidence that raises the probability to at least $4 / 5$ ". But expressions like those leave it open how exactly evidence-IP is to be measured. Consider the following measures of evidence-IP:

$$
\begin{aligned}
& e_{d}(H, E)=\operatorname{Pr}(H \mid E)-\operatorname{Pr}(H) \\
& e_{K O}(H, E)=\frac{\operatorname{Pr}(E \mid H)-\operatorname{Pr}(E \mid \neg H)}{\operatorname{Pr}(E \mid H)+\operatorname{Pr}(E \mid \neg H)}
\end{aligned}
$$

The first of these measures is the "difference" measure. The second is the "KemenyOppenheim" measure. ${ }^{13}$ Suppose that $E$ entails $H$ and thus is evidence-IP for $H$ (assuming that neither $E$ nor $H$ has an extreme unconditional probability). It follows by $e_{d}$ that whether the degree of evidence-IP is high or low depends on whether $\operatorname{Pr}(H)$ is high or low. If $\operatorname{Pr}(H)$ is high, then the degree of evidence-IP is low. If $\operatorname{Pr}(H)$ is low, then the degree of evidence-IP is high. It follows by $e_{K O}$, in contrast, that the degree of evidence-IP is high, indeed, is maximal at 1 , regardless of whether $\operatorname{Pr}(H)$ is high or low.

$\mathrm{T} \& \mathrm{C}$ presumably hold that $\mathrm{EEE}_{\mathrm{NDC}}$ is true regardless of which of the leading measures of evidence-IP in the literature is assumed (otherwise, presumably, they would have specified how degree of evidence-IP is to be measured). I shall assume $e_{d}$ and thus shall assume that in the case of John and the departmental meeting the degree to which $H_{1}$ is evidence-IP for $\mathrm{H}_{2}$ is 0.05 . But nothing of importance for my purposes hinges on this, since all the main points below would hold mutatis mutandis if $e_{K O}$ or any alternative measure of evidence-IP (in the literature) were assumed instead.

Now, continuing with the second version of the case of John and the departmental meeting, let $H^{*}$ be the proposition that there is a proposition $E^{*}$ such that $E^{*}$ is true and is evidence-IP for $H_{2}$ to degree 0.05 . There is no reference to $H^{*}$ in the probability distribution above. It turns out, though, that $H^{*}$ is logically equivalent (in the context) to $H_{1}$. (See Appendix for details.) It follows immediately that:

\footnotetext{
${ }^{13}$ See Roche and Shogenji (2014a) for a list of the main measures of evidence-IP (or "confirmation") in the literature.
} 
(m) $\quad \operatorname{Pr}\left(H^{*} \mid E\right)=9 / 10>2 / 3=\operatorname{Pr}\left(H^{*}\right)$

(n) $\quad \operatorname{Pr}\left(H_{2} \mid H^{*}\right)=9 / 10>85 / 100=\operatorname{Pr}\left(H_{2}\right)$

(o) $\quad \operatorname{Pr}\left(H_{2} \mid H^{*} \& E\right)=9 / 10>85 / 100=\operatorname{Pr}\left(H_{2}\right)$

(p) $\quad \operatorname{Pr}\left(H_{2} \mid E\right)=81 / 100<85 / 100=\operatorname{Pr}\left(H_{2}\right)$

By (m) it follows that $E$ is evidence-IP for $H^{*}$ to degree $7 / 30$ where $H^{*}$ is the proposition that there is a proposition $E^{*}$ such that $E^{*}$ is true and is evidence-IP for $H_{2}$ to degree 0.05 . By (n) it follows that $H^{*}$ is evidence-IP for $H_{2}$ to degree 0.05 . By (o) it follows that $H^{*} \& E$ is evidence-IP for $H_{2}$ to degree 0.05 . By (p) it follows that $E$ is not evidence-IP for $H_{2}$. Hence $\mathrm{EEE}_{\mathrm{NDC}}$, as with $\mathrm{EEE}^{*}{ }_{\mathrm{NDC}}$, is open to counterexample.

$\mathrm{T} \& \mathrm{C}$ close their discussion by giving a gloss of $\mathrm{EEE}_{\mathrm{NDC}}$ and writing (where notation has been slightly modified):

Evidence that there is ... evidence for $\mathrm{H}_{2}$ is itself evidence for $\mathrm{H}_{2}$ when it is not at the same time a defeater for the support that the proposition that there is evidence for $\mathrm{H}_{2}$ provides to $\mathrm{H}_{2}$. Doesn't quite roll off the tongue, but it has not yet been shown false. (T\&C 2017, p. 110)

They can no longer say that.

Now return to the point from Section 2 that there are counterexamples to the thesis that NDC is sufficient for transitivity in evidence-IP. It turns out that things are different in the special case where $E$ entails $H_{1}$. The following holds without exception:

$$
\begin{array}{lll}
\text { TIP* }_{\text {NDC }} \text { If } & \text { (i) } \operatorname{Pr}\left(H_{1} \mid E\right)>\operatorname{Pr}\left(H_{1}\right), \\
& \text { (ii) } \operatorname{Pr}\left(H_{2} \mid H_{1}\right)>\operatorname{Pr}\left(H_{2}\right), \\
& \text { (iii) } \operatorname{Pr}\left(H_{2} \mid H_{1} \& E\right)>\operatorname{Pr}\left(H_{2}\right),
\end{array}
$$

and

(iv) $E$ entails $H_{1}$,

then (v) $\operatorname{Pr}\left(H_{2} \mid E\right)>\operatorname{Pr}\left(H_{2}\right)$.

Suppose that (i)-(iv) in TIP* ${ }_{\mathrm{NDC}}$ all hold. It follows from (iv) that $E$ is logically equivalent to $H_{1} \& E$. Hence, given (iii), it follows that $\operatorname{Pr}\left(H_{2} \mid E\right)>\operatorname{Pr}\left(H_{2}\right)$. Should this be welcome news to $\mathrm{T} \& \mathrm{C}$ ?

No. Any case where (iv) in TIP* ${ }_{\text {NDC }}$ holds is a case where (v) holds if and only if (iii) holds. It does not matter whether (i) and (ii) hold. This can be seen by noting that the following variant of TIP* ${ }_{\text {NDC }}$ also holds without exception: 


$$
\begin{array}{ll}
\text { TIP**NDC If } & \text { (i*) } \operatorname{Pr}\left(H_{1} \mid E\right)=\operatorname{Pr}\left(H_{1}\right), \\
& \text { (ii*) } \operatorname{Pr}\left(H_{2} \mid H_{1}\right)=\operatorname{Pr}\left(H_{2}\right), \\
& \text { (iii) } \operatorname{Pr}\left(H_{2} \mid H_{1} \& E\right)>\operatorname{Pr}\left(H_{2}\right),
\end{array}
$$

and

(iv) $E$ entails $H_{1}$, then (v) $\operatorname{Pr}\left(H_{2} \mid E\right)>\operatorname{Pr}\left(H_{2}\right)$.

$\mathrm{TIP}_{\mathrm{NDC}}$, as with TIP* ${ }_{\mathrm{NDC}}$, is a TIP thesis in name only. ${ }^{14}$

T\&C could modify EEE $\mathrm{NDC}_{\mathrm{N}}$ along the lines of TIP* ${ }_{\mathrm{NDC}}$. Then it would not be open to counterexample. But, at the same time, it would be an EEE thesis in name only.

A better tack would be to abandon the no-defeaters approach in favor of the screeningoff approach. EEE $_{S O C}$ is not open to counterexample and is not an EEE thesis in name only.

\section{Conclusion}

SOC is sufficient for transitivity in evidence-IP. Further, unlike TC (the condition that $E$ is evidence-IP for $H_{2}$ ), SOC can help explain in a given case why $E$ confirms $H_{2}$, and can help in verifying in a given case that $E$ confirms $H_{2}$. Thus SOC is fit for use in EEE theses. NDC, by contrast, is not sufficient for transitivity in evidence-IP and thus is not fit for use in EEE theses. These points are borne out by the fact that $\mathrm{EEE}_{\mathrm{SOC}}$ holds without exception whereas $\mathrm{EEE}_{\mathrm{NDC}}$ does not.

\section{Acknowledgments}

I wish to thank an anonymous reviewer, an audience at the 12th Annual Formal Epistemology Workshop, Juan Comesaña, Tomoji Shogenji, and Eyal Tal for helpful very feedback.

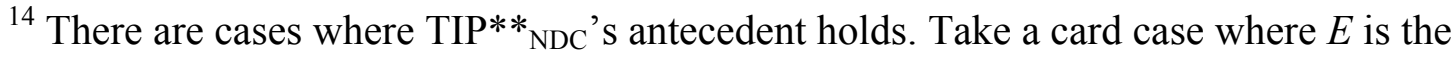
proposition that the card drawn is a Red, $H_{1}$ is the proposition that the card drawn is a Jack or not a Jack, and $H_{2}$ is the proposition that the card drawn is a Diamond. Here $\operatorname{Pr}\left(H_{1} \mid E\right)=$ $1=\operatorname{Pr}\left(H_{1}\right), \operatorname{Pr}\left(H_{2} \mid H_{1}\right)=1 / 4=\operatorname{Pr}\left(H_{2}\right), \operatorname{Pr}\left(H_{2} \mid H_{1} \& E\right)=1 / 2>1 / 4=\operatorname{Pr}\left(H_{2}\right)$, and $E$ entails $H_{1}$.
} 


\section{Appendix}

Take the probability distribution given above in Section 3. First, it follows that $H^{*}$ is logically equivalent (in the context) to a disjunction with the following disjuncts:

(q) $\quad H_{1}$

(r) $\quad\left(E \& H_{2}\right) \vee H_{1}$

(s) $\quad\left(E \& H_{1}\right) \vee\left(E \& H_{2}\right) \vee\left(H_{1} \& H_{2}\right)$

(t) $\quad\left(E \& H_{1}\right) \vee\left(E \& H_{2}\right) \vee\left(H_{1} \& \neg H_{2}\right)$

(u) $\quad\left(E \& H_{1}\right) \vee\left(E \& H_{2}\right)$

(v) $\quad\left(E \& H_{1}\right) \vee\left(H_{1} \& H_{2}\right)$

(w) $\quad\left(E \& H_{1}\right) \vee\left(H_{1} \& \neg H_{2}\right)$

(x) $\quad\left(E \& H_{1}\right)$

This is because there are exactly 256 distinct Boolean propositions constructible from one or more of $E, H_{1}$, and $H_{2}$, each of (q)-(x) is evidence-IP for $H_{2}$ to degree 0.05 , and none of the remaining 248 distinct Boolean propositions constructible from one or more of $E, H_{1}$, and $\mathrm{H}_{2}$ is evidence-IP for $\mathrm{H}_{2}$ to degree $0.05 .{ }^{15}$ Second, each of (q)-(x) entails and is entailed by $H_{1}$. The key here is that $H_{1}$ entails (in the context) $E$ and is entailed by (in the context) $E \&$ $\mathrm{H}_{2}$. QED

\section{References}

Comesaña, J., and Tal, E. (2015). Evidence of evidence is evidence (trivially). Analysis, 75, 557-559.

Douven, I. (2011). Further results on the intransitivity of evidential support. Review of Symbolic Logic, 4, 487-497.

\footnotetext{
${ }^{15}$ This is all straightforward (though tedious) to verify on Mathematica using "BooleanFunction", "BooleanConvert", and Fitelson's "PrSAT". See Fitelson (2008) for discussion of PrSAT.
} 
Fitelson, B. (2008). A decision procedure for probability calculus with applications. Review of Symbolic Logic, 1, 111-125.

Fitelson, B. (2012). Evidence of evidence is not (necessarily) evidence. Analysis, 72, 85-88.

Hempel, C. (1965). Studies in the logic of confirmation. In C. Hempel, Aspects of scientific explanation and other essays in the philosophy of science (pp. 3-46). New York: Free Press.

Kotzen, M. (2012). Dragging and confirming. Philosophical Review, 121, 55-93.

Moretti, L. (2016a). Tal and Comesaña on evidence of evidence. The Reasoner, 10, 38-39.

Moretti, L. (2016b). Evidence of expert's evidence is evidence. Episteme, 13, 209-218.

Roche, W. (2012a). A weaker condition for transitivity in probabilistic support. European Journal for Philosophy of Science, 2, 111-118.

Roche, W. (2012b). Transitivity and intransitivity in evidential support: Some further results. Review of Symbolic Logic, 5, 259-268.

Roche, W. (2014). Evidence of evidence is evidence under screening-off. Episteme, 11, 119124.

Roche, W. (2015). Evidential support, transitivity, and screening-off. Review of Symbolic Logic, 8, 785-806.

Roche, W., and Shogenji, T. (2014a). Dwindling confirmation. Philosophy of Science, 81, 114-137.

Roche, W., and Shogenji, T. (2014b). Confirmation, transitivity, and Moore: The ScreeningOff Approach. Philosophical Studies, 168, 797-817.

Shogenji, T. (forthcoming). Mediated confirmation. British Journal for the Philosophy of Science.

Tal, E., and Comesaña, J. (2017). Is evidence of evidence evidence? Nous, 51, 95-112. 